\title{
¿SON LOS HECHOS SOCIALES UNA CLASE DE HECHOS MENTALES? \\ Una crítica materialista a la ontología social de John R. Searle
}

\author{
José Antonio Noguera
}

Universidad Autónoma de Barcelona

\begin{abstract}
RESUMEN
El presente artículo lleva a cabo un análisis crítico de algunos aspectos de la obra de John R. Searle La construcción de la realidad social (1995). Partiendo del acuerdo con Searle sobre la necesidad de abandonar el llamado "construccionismo social», se valora hasta qué punto la argumentación del autor resulta exitosa en ese empeño. A este respecto, se defienden las siguientes tesis: 1) La ontología social de Searle está parcialmente lastrada por un inadecuado mentalismo, esto es, por la reducción de todos los hechos sociales a hechos mentales o representaciones superpuestas a hechos «brutos». 2) El mentalismo de Searle no le aleja lo suficiente de los construccionistas sociales, sino que su desarrollo coherente acaba teniendo consecuencias construccionistas e idealistas, a pesar suyo. 3) Para superar estas limitaciones, se debería demostrar que hay hechos sociales que no son ni hechos brutos, ni hechos mentales, ni simples combinaciones de ambos; se sostendrá que un concepto analíticamente reconstruido de praxis puede ser un buen punto de partida para desarrollar esta estrategia, que puede ser un paso en la construcción de una ontología social materialista.
\end{abstract}

\section{INTRODUCCIÓN: EL DESAFÍO ONTOLÓGICO DE SEARLE}

Estas páginas surgen de una inquietud y de una sorpresa. La inquietud, que ya dura unos años, es la de mostrar que hay algo profundamente equivocado en los enfoques sociológicos "construccionistas» (o como se prefiera llamarlos), algunos de los cuales tienen como inspiración y origen, entre otros 
muchos, el conocido libro de Berger y Luckmann La construcción social de la realidad (1966); y lo que creo que hay de equivocado en ellos, para decirlo en tres palabras, es una ontología social idealista. La sorpresa, en cambio, se produjo cuando, tras haber leído el libro de John R. Searle La construcción de la realidad social (1995), del que, según todos los indicios, cabía esperar una crítica devastadora del "construccionismo», me encontré no sólo con que Searle no llevaba esa crítica a donde yo esperaba — cosa que, sin duda, no tenía por qué hacer-, sino además con que su planteamiento conducía, en el fondo, a consecuencias ontológicas muy cercanas a las que provocaban mi insatisfacción con Berger y Luckmann y con los "construccionistas», esto es, a consecuencias idealistas. De modo que lo aquí me propongo es criticar la obra de Searle desde un punto de vista materialista, como insuficientemente alejada del mundo del «construccionismo social»". Esta crítica nos conducirá a algunas consideraciones más amplias sobre la ontología de los hechos sociales.

Resulta sorprendente que en algunas ocasiones y contextos se haya considerado el libro de Searle como una crítica del de Berger y Luckmann. Desde luego, no se trata de una crítica explícita, pues estos últimos no aparecen citados ni una sola vez, y lo cierto es que, ante las insistentes comparaciones, el propio Searle ha manifestado que desconocía su existencia cuando escribió su propio libro:

«De hecho, no estaba respondiendo al libro de Berger y Luckmann La construcción social de la realidad, ni me inspiré en él. De hecho, no tuve noticia de su libro hasta que hube acabado el primer borrador del mío. Tras mis conferencias Kant en Stanford, diversas personas me indicaron que ya existía un libro con un título relacionado. Eché un vistazo a ese libro, pero lo encontré tan absolutamente diferente de lo que yo estaba intentando hacer que ni lo utilicé ni me referí a él» (Searle, 1997b: 106-107).

No le faltaba razón a Searle: el libro de Berger y Luckmann es totalmente diferente del suyo en el título, el enfoque y el contenido, así como muy inferior en cuanto a formalización y rigor lógico; no en vano la tradición de la que partían aquellos autores no era la analítica, sino la fenomenológica, corriente filosófica que Searle ha criticado duramente en varias ocasiones (véase, por ejemplo, Searle, 2001b). Pero lo que me interesa mostrar en las páginas que siguen es que, por lo que hace a su ontología social, no hay tampoco una crítica implícita al "construccionismo" de Berger y Luckmann en el libro de Searle.

Como ya he dicho, Searle parte de la tradición de la filosofía analítica; sus preocupaciones y su merecida fama como filósofo tienen que ver con la filoso-

1 Para una crítica en la misma línea del libro de Berger y Luckmann puede verse Noguera (1999). El análisis crítico más riguroso, exhaustivo y lúcido del variopinto mundo del «construccionismo" y de las tesis de la "construcción social» es, sin duda, el de Hacking (1999), quien, sin embargo, no se adentra del todo en el terreno que aquí intentaré transitar. 
fía del lenguaje y de la mente, campos ambos en los que ha hecho aportaciones de peso, algunas de las cuales pueden calificarse sin vacilar de clásicas (como Actos de habla o Intencionalidad). La construcción de la realidad social, por su parte, expande esas preocupaciones al ámbito de la filosofía de la sociedad, y, a mi entender, constituye un impresionante esfuerzo conceptual que reúne todas las virtudes de la tradición analítica: su argumentación es transparente, directa, precisa y lógicamente rigurosa; su talante intelectual, serio, elegante y honesto $^{2}$. Se trata, sin duda, de una teoría seductora por su simplicidad, por su generalidad, y porque clarifica cuestiones cruciales para la ciencia social mejor de lo que lo han hecho muchos venerados sociólogos, contemporáneos o no. Searle, a pesar de no ser un sociólogo ni un teórico social, identifica los problemas cruciales con perspicacia; se enfrenta a ellos a cara descubierta, sin retórica ni ambigüedades; no retuerce la sintaxis, y destierra las «cajas negras» y vaguedades tan frecuentes en otros teóricos sociales contemporáneos al limbo de lo ininteligible.

No expondré aquí en detalle el contenido del libro por dos razones: porque es mejor remitir directamente a su lectura, y porque iré desgranándolo a lo largo de mi crítica. Simplemente enunciaré ahora su pretensión general y sus tesis básicas. Como afirma Hacking (1997), la empresa de Searle no es tanto sociológica como lógica y ontológica: lo que le interesa es estudiar las condiciones de posibilidad de los hechos sociales e institucionales, así como la estructura lógica que tienen esas condiciones. Las tesis básicas del libro son las siguientes: podemos distinguir entre "hechos brutos» (independientes de los estados mentales y de las instituciones humanas, como "hay nieve en el Everest») y "hechos institucionales» (que sí requieren estados mentales humanos para existir, como "Zutana y yo estamos casados»). Estos hechos institucionales (que para Searle son una sub-clase de los sociales) se definen mediante tres conceptos que forjan la arquitectura del libro:

1) La intencionalidad colectiva (que es lo que define a los hechos sociales, tanto en el ser humano como en las demás especies animales), esto es, aquel tipo de estado mental intencional que se tiene sólo en tanto que compartido con otros individuos.

2) La asignación de funciones de status, es decir, la imposición de una función a algún objeto u hecho previamente existente, con la peculiaridad de que las características físicas de ese objeto no bastan por sí solas para cumplir esa función, sino que es necesaria la intencionalidad colectiva continuada a tal efecto.

3) Las reglas constitutivas, que son aquellas que no se limitan a regular un comportamiento ya existente, sino que constituyen su condición de

2 Según una afortunada metáfora de Hacking (1997: 90), «cuando algunos lectores se quejan de a dónde les ha llevado Searle, son como gente que lee la letra pequeña de sus pólizas de seguros después de un accidente». 
posibilidad (como las reglas de un juego); las reglas constitutivas a la vez constituyen los hechos institucionales y describen su estructura lógica, según la fórmula «X cuenta como $\mathrm{Y}$ en el contexto C».

Un ejemplo sencillo $-\mathrm{y}$ recurrente en el libro- es el del dinero: el trozo de papel que tengo en el bolsillo es un hecho bruto, con unas propiedades físico-químicas determinadas, pero el hecho de que ese trozo de papel sea «dinero" (y pueda ser utilizado como medio de cambio) es un hecho institucional, que implica intencionalidad colectiva (no existiría sin la creencia compartida de que es dinero), y está constituido como tal por una asignación de función de status según una regla constitutiva: «los trozos de papel de tales y tales características $(\mathrm{X})$ cuentan como dinero $(\mathrm{Y})$ en el contexto del país $(\mathrm{P}) »$; las propiedades físicas del trozo de papel $(\mathrm{X})$ no son suficientes en términos causales para cumplir la función Y (ser dinero) si no existiera esta asignación de status (como sí lo serían en el caso de un destornillador o un automóvil, a los cuales asignamos "funciones causales», no de status). Estas reglas constitutivas se pueden iterar indefinidamente, esto es, $\mathrm{X}$ bien puede ser un hecho institucional previo, pero al final de la cadena siempre encontraremos algún hecho bruto puramente físico.

El razonamiento de Searle va más allá de lo anterior, pero no adelantemos argumentos. De momento, señalemos que tal planteamiento ha generado en poco tiempo (seis años) un debate considerable en numerosos foros académicos y revistas de filosofía y ciencias sociales anglosajonas, alemanas y francesas ${ }^{3}$. En tales discusiones, tres han sido los principales blancos de sus críticos:

1) Su concepto de intencionalidad colectiva, que muchos han visto como defectuoso o inconsistente con el individualismo metodológico que dice suscribir el autor (Hornsby, 1997; Corsten, 1998; Waldenfels, 1998; Celano, 1999; Heidemann, 1999; Meijers, 2000).

2) Su concepto de institución, y concretamente el papel de las reglas constitutivas, que se han visto como circulares o tautológicas (Tuomela, 1997; Corsten, 1998; Waldenfels, 1998; Lagerspetz, 1999; Celano, 1999; Smith, 2001).

3) Su defensa de la prioridad lógica de los hechos brutos sobre los institucionales, o del análisis lógico sobre el fenomenológico (Ruben, 1997; Waldenfels, 1998; Lagerspetz, 1999; Dreyfus, 2001a y 2001b; Smith, 2001).

A decir verdad, muchas de las críticas que ha recibido Searle por tales motivos no acaban de hacer justicia a su planteamiento o lo malentienden en

Concretamente, y sin ser exhaustivo, se han publicado simposios sobre el libro en Philosophy and Phenomenological Research (1997), History of the Human Sciences (1997), Philosophy of the Social Sciences (1998), Analyse und Kritik (1998/99) y Revue Internationale de Philosophie (2001). 
varios sentidos, de manera que nuestro autor logra zafarse con notable facilidad y brillantez de la mayoría de ellas (ver Searle 1997a, 1997b, 1998, 2001b, $2001 c$ y 2001d). La crítica que intentaré articular, basada en reivindicar el carácter ontológicamente constitutivo de la práctica para los hechos institucionales, ha sido sugerida pero no desarrollada como tal por algunos de esos críti$\cos ^{4}$. Vaya por delante que no entraré a analizar los razonamientos de Searle sobre la intencionalidad colectiva, el "trasfondo» (background), el papel explicativo de las normas en la conducta, o el realismo y la verdad como correspondencia (cuestiones que, con matices, me parecen bien resueltas en el libro).

\section{EL MENTALISMO DE SEARLE}

En su respuesta a Barnes (Searle, 2001c: 296), Searle afirma, entre otras cosas, lo siguiente: "el hecho de que la realidad social e institucional esté constituida como tal por las actitudes que tomamos hacia ellas no convierte a mi ontología en esencialmente epistémica, aunque sí la hace esencialmente mentalista». No podemos sino estar de acuerdo en que así es: el supuesto básico de Searle es que los estados mentales son los componentes constitutivos básicos de esa realidad, además de los hechos brutos independientes de los seres humanos que le sirven de base material ${ }^{5}$.

Searle no es, sin embargo, un reduccionista radical: al contrario, defiende que lo mental «emerge» de lo físico y lo biológico, y de la misma forma lo cultural "emerge» de lo biológico — «la cultura es la forma que toma la biología» (1995: 231)_. Obsérvese, sin embargo, la diferencia esencial entre Searle y Durkheim u otros teóricos holistas e idealistas: en primer lugar, para Searle la cultura emerge de lo biológico, no de lo mental; la cultura es mental, y en buena parte consiste en representaciones mentales, no constituye para Searle un nivel de realidad emergente nuevo o distinto respecto del mental, aunque sí lo sea respecto del biológico: no es necesario suponer una realidad ontológicamente sui generis para dar cuenta de la realidad social e institucional, nos basta con los hechos físicos brutos y los estados mentales de los seres humanos para dar cuenta de la estructura ontológica de esa realidad ${ }^{6}$. En segundo lugar, Searle ignora totalmente el sacrosanto principio durkheimiano de «explicar lo

${ }^{4}$ Por ejemplo, el siempre perspicaz Hacking (1997: 85) afirma: «Hay muy poco "hacer” en el libro de Searle» ("There is very little doing in Searle's book»); véanse también Hund (1998) y Wettersten (1998).

5 En una entrevista en la revista francesa Le Débat (Searle, 2000b), Searle abundaba en esa tesis cuando se le planteaba: «Su teoría implicaría que más allá de la naturaleza física, no hay más que las "representaciones"». Respuesta de Searle: "En cierto sentido, eso es justamente lo que digo» («c'est bien ce que je dis»).

${ }^{6}$ Compárese esto con el uso que hacía Durkheim (1898) de la analogía de la «emergencia» para hacer surgir lo social como nivel autónomo de realidad a partir de lo mental o de la conciencia individual. 
social por lo social» (Durkheim, 1895). Searle cree que la base de lo social son hechos brutos y hechos mentales, y de la misma forma que la neurofisiología cerebral humana se distingue de la de otras especies en el hecho de que toma la forma de "conciencia», así también la cultura humana se diferencia de la intencionalidad colectiva o conducta social de otras especies en el hecho de expresarse lingüística o simbólicamente.

Las definiciones estipulativas que da Searle de "hecho social» $\mathrm{y}$ «hecho institucional» confirman el carácter mentalista de su empresa. En la taxonomía de hechos que elabora (1995: 132), los hechos sociales aparecen como una subclase de los mentales, aquellos en los que hay intencionalidad colectiva (lo que Searle denomina we-intentions, intenciones que son individuales - como todas- pero que se expresan en primera persona del plural, puesto que no existirían si no fueran compartidas con similares intenciones de otros individuos). Se define, por tanto, el hecho social por referencia a estados mentales de una clase determinada. Una consecuencia inmediata $-\mathrm{y}$ contraintuitiva para muchos sociólogos - es que los animales pueden ser sociales o dar lugar a hechos sociales: una manada de hienas acosando y cazando a un león constituye un hecho social para Searle, ya que envuelve intencionalidad colectiva. Pero hay otra consecuencia, a mi juicio mucho menos inocua, que los críticos no han visto (o, si la han visto, no les ha preocupado tanto), a saber: que hay toda una serie de hechos que la sociología tradicional no duda en considerar «sociales» que quedarían automáticamente fuera de la definición de Searle; cualquier acción estratégica individual, por ejemplo, no sería un hecho social, al no involucrar intencionalidad colectiva: sería un hecho mental intencional pero no social. Sin duda, estamos muy lejos de la definición clásica que dio Max Weber de la acción social.

Pero lo cierto es que Searle, más que por los hechos sociales, se interesa fundamentalmente por un sub-tipo de éstos, que denomina «hechos institucionales» ${ }^{7}$. Ya los hemos definido en la introducción: en estos hechos se asigna a un hecho u objeto previo (que puede ser bruto o ya institucional) una función de status (no causal, esto es, que es necesaria para que el objeto pueda cumplir la función, puesto que no podría cumplirla exclusivamente en virtud de sus meras características físicas) en un determinado contexto: esta asignación se puede expresar lógicamente con la regla "X cuenta como Y en el contexto C». Evidentemente, es necesario el lenguaje, en un sentido amplio de "capacidad de simbolización», para llevar a cabo esta asignación. Lo que interesa destacar ahora es que, para Searle, lo que constituye los hechos institucionales es precisamente algún grado de aceptación colectiva de una regla constitutiva que toma esa forma. Esta aceptación de la regla crea lo que Searle denomina poderes deónticos, a saber, toda una serie de derechos, obligaciones, capacidades, requerimientos, prohibiciones, etc., que estructuran la realidad institucional. Deje-

7 De hecho, como afirma Hornsby (1997), el libro bien podría titularse «La construcción de la realidad institucional». 
mos para después el espinoso concepto de "aceptación colectiva». De momento, queda claro de nuevo que son estados mentales (de aceptación o creencia) los que constituyen la sustancia de las instituciones para Searle, ese "algo más» que los hechos brutos necesitan para que se generen hechos institucionales. Las instituciones existen en la medida en que creamos que existen y las aceptemos como tales. Los hechos sociales e institucionales son, para Searle, hechos mentales por definición, constituidos esencialmente por contenidos de la mente o de la conciencia ${ }^{8}$. Así, resulta coherente la afirmación de que, para asignar funciones de status, «el acuerdo, la aceptación humana, y otras formas de intencionalidad colectiva, resultan condiciones necesarias suficientes» (ibid.: 68). El libro de Searle bien podría titularse «La construcción mental de la sociedad», como lúcidamente ha advertido De Lara (1997: 117).

Queda claro ahora por qué el planteamiento de Searle resulta tan extraño para los sociólogos formados en la teoría social clásica. Las definiciones que hace de "hecho social" y de "hecho institucional» son tan atípicas y contraintuitivas para esa tradición que inducen a interminables confusiones en muchos de los debates habidos, así como a hacer críticas irrelevantes que no se atienen a los términos definitorios de Searle. A mi juicio, la crítica suele ser más fructífera cuando acepta los propios términos del criticado (aunque sea para acabar dándoles la vuelta); así que partiremos en principio de aceptar los términos y las definiciones que fija Searle (ya que, por otro lado, se trata de simples estipulaciones), e intentaremos ver a dónde nos llevan.

\section{LAS CONSECUENCIAS «CONSTRUCCIONISTAS» DEL MENTALISMO DE SEARLE}

Compárense las dos afirmaciones siguientes:

«[Los hechos institucionales] son hechos sólo merced al acuerdo humano (...) [y] existen sólo porque creemos que existen» (Searle, 1995: 21).

«La sociedad sólo existe en la medida en que los individuos son conscientes de ella» (Berger y Luckmann, 1966: 96).

${ }^{8}$ Aun así, hay ocasiones en las que Searle, contrariamente a lo que acostumbra, es ambiguo: por ejemplo, cuando habla del "componente mental» de los hechos institucionales (1995: 46), lo que da pie a preguntar: ¿cuál es el otro o los otros componentes? Lo mismo ocurre cuando dice (por ejemplo, ibid.: 51) que sólo "parte» del hecho de que algo sea dinero —o una fiesta- es que se piense que lo es: bien, ¿cuál es la otra parte? Conforme uno avanza en la lectura y la interpretación de Searle, la conclusión se abre paso: la otra parte, o el otro componente, es el hecho bruto. Pero entonces, si, como admite Searle, la mayoría de los hechos institucionales lo son por iteración, esto es, por asignación de función de status a un hecho institucional previo, y no directamente a un hecho bruto, aunque al final de la cadena de iteraciones tengamos que encontrarnos con los hechos brutos, entonces la inmensa mayoría de los hechos institucionales serán plena y exclusivamente hechos mentales, y no tendrán componentes físicos en absoluto. 
Si a primera vista no parece haber mucha diferencia entre ambas, es por una razón bien sencilla: porque no la hay en absoluto. Sostendré, en efecto, que el análisis de Searle implica un buen grado de "construccionismo social» a pesar suyo. ¿Cómo, entonces, puede verse a veces su libro como una crítica del "construccionismo"?

Aunque Searle no utiliza nunca la expresión "construccionismo», en alguna ocasión habla de «constructivismo social» (por ejemplo, pp. 196-197), sobre todo en los tres últimos capítulos del libro, cuando defiende el realismo ontológico y la teoría de la verdad como correspondencia. Su argumento viene a ser el siguiente: la realidad institucional es "construida", pero siempre presupone una realidad bruta previa a partir de la cual se pueda construir algo; dicho más formalmente, los hechos brutos tienen primacía lógica sobre los hechos institucionales, pues al final de la cadena de asignaciones de funciones de status iteradas siempre habrá hechos brutos no construidos. Y esos hechos brutos, según el realismo, "tienen una manera de ser que es lógicamente independiente de todas las representaciones humanas» (ibid.: 164-165); en cambio, las instituciones no son independientes de ellas (estrictamente: no son independientes de todas las representaciones humanas, aunque puedan serlo de las nuestras, o de las de Fulano o el grupo X).

La crítica de Searle resulta devastadora para quien niegue que existan "hechos brutos», o que tengan algo que ver con los hechos institucionales; pero al mismo tiempo es decepcionante para quien crea que los hechos institucionales son «reales» en algún otro sentido que su «ser tenidos por reales». Pareciera que, para Searle, lo «real» de la realidad institucional es simplemente el hecho de que descanse en última instancia sobre la realidad bruta (la realidad institucional es ontológicamente subjetiva, aunque pueda ser epistémicamente objetiva: que alguien esté casado es un hecho objetivo comprobable empíricamente para nosotros, pero su ocurrencia no ha sido independiente de estados mentales humanos y, por tanto, es ontológicamente subjetivo). Su crítica al "construccionismo", por tanto, se limita sólo a mostrar la "primacía lógica» de los hechos brutos sobre los institucionales. En definitiva, si a la mayoría Searle le parece demasiado realista por lo que hace a la realidad natural, a otros, en cambio, nos puede parecer demasiado poco realista por lo que hace a la social.

En efecto, en el ámbito de lo institucional, la ontología de Searle no se diferencia casi nada de la de muchos "construccionismos». Frazer (1997) da en el clavo cuando dice que si, para Searle, los hechos institucionales dependen del reconocimiento continuado del suficiente número de personas de la "comunidad relevante» (algo ambiguo, pues ¿cuántos son «suficiente»?), ello nos deja con la pregunta de si el resto de miembros de la comunidad, que no "reconocen» la institución, tienen razón o no al considerarla no-real. Searle (2001d) ha respondido a una crítica similar de Barry Smith (2001) aduciendo que su teoría no busca resolver los conflictos sociales sobre qué instituciones hay que reconocer, sino simplemente describir la estructura lógica de ese con- 
flicto, así como qué quiere decir que una institución "existe»; ¡pero si esto es así, la pretensión ontológica de la teoría queda seriamente dañada en favor de la meramente lógica! En cualquier caso, y como apunta Frazer, «esto se parece mucho a factores sociales penetrando en la ontología (...) de los hechos institucionales: sin acuerdo la institución puede desvanecerse» (1997: 76). ¡Pero esto es lo que han dicho siempre los «construccionistas» como Berger y Luckmann, e incluso otros mucho menos moderados que ellos!

Y es que la crítica de Searle se puede aplicar únicamente a un «construccionismo radical» o "universal»", lo cual resulta descorazonador, puesto que prácticamente ningún "construccionista» es tan radical o tan «universal» como para decir que no existe hecho bruto alguno y que todo - absolutamente todoson hechos "construidos». A la postre, Searle estaría sosteniendo algo muy parecido a lo que afirman la mayoría de los "construccionistas», a saber: que los hechos sociales (o institucionales) son constituidos (no meramente causados) por nuestras creencias o estados mentales (esto es, una ontología social idealista o mentalista). Como nota Osborne (1997: 101), a Bruno Latour le encantaría la frase de Searle de que quien tiene el fusil en la mano suele ser el menos poderoso, y viceversa ${ }^{10}$. Aunque en última instancia, y reconstruyendo el proceso de iteración, lleguemos siempre a hechos brutos a partir de cualquier hecho institucional, eso al "construccionista» le importa poco en la medida en que podemos estar muy alejados de lo material: según la divertida metáfora de Osborne (ibid.), seríamos como esos personajes de dibujos animados que rebasan el borde de un abismo y siguen corriendo en el aire como si nada: seguro que alcanzarán el suelo al final, pero la caída puede ser dura; pues bien, si el "suelo» está tan lejos, ¿es tan importante?: ésta es, en el fondo, la pregunta "construccionista», y, lamentablemente, no veo nada en la teoría de Searle que pueda utilizarse contra ella.

A estas alturas, alguien puede estar ya preguntándose algo así como "¿pero qué es lo que hay de malo en ser "construccionista" o "idealista" en el sentido definido?». Muy bien, vayamos algo más lejos: en su libro de 1966, Berger y Luckmann aludían al vudú y las "posesiones demoníacas» en Haití como ejemplo de "construcción social de la realidad»; ¿podría este ejemplo entrar dentro de la definición de "hecho institucional» de Searle, esto es, contar como una asignación de función de status? Berger y Luckmann decían lo siguiente:

«Ni los dioses del vudú ni la energía libidinal pueden existir más que dentro del mundo tal como es definido en los contextos sociales respec-

9 Véase a este respecto la útil clasificación de «niveles de construccionismo» que hace Hacking (1999: 45 ss.), así como su discusión del «construccionismo universal» (ibid.: 52 ss.).

${ }_{10}$ Por cierto que Barry Barnes (2001: 263), uno de los fundadores del llamado «programa fuerte» en la sociología del conocimiento y de la ciencia, afirma que su perspectiva es "estrechamente parecida" ("closely analogous») a la de Searle, y muestra cómo sus respectivos argumentos no difieren mucho (ibid.: 265). 
tivos. Pero en estos contextos sí existen en virtud de una definición social y son interiorizados como realidades en el decurso de la socialización. Los campesinos haitianos son poseídos y los intelectuales de Nueva York son neuróticos» (Berger y Luckmann, 1966: 197-198; cursivas originales).

Quizá estemos ya en una situación en la que lo que voy a decir parezca algo ingenuo o incluso atrevido, pero entre gentes que se autodenominan científicos la afirmación de que alguien es poseído por un demonio me parece, en el mejor de los casos, un juego de palabras y, en el peor, una frivolidad: sencillamente, los demonios y las posesiones demoníacas no existen, ni en Haití ni en ningún otro lugar. Mi problema es que no veo cómo la teoría de la realidad social de Searle podría evitar la afirmación de Berger y Luckmann, o cómo se puede diferenciar en absoluto de ella (a pesar de que estoy seguro de que el escucharla le descompondría el gesto). Veamos: si los «síntomas X» cuentan como "posesión demoníaca» $(\mathrm{Y})$ en el contexto $(\mathrm{C})$ de Haití (y dado que, como dice Searle insistentemente, los agentes no tienen por qué ser conscientes de lo que realmente están haciendo cuando asignan funciones de status, y pueden tener todo tipo de ideas falsas sobre cómo funciona), entonces la "posesión demoníaca» se convierte en un hecho institucional tan cierto y objetivo (aunque sea epistémicamente) como el dinero o el matrimonio, $y$, en este sentido, existen posesiones demoníacas exactamente igual que existe dinero o matrimonios, dado que son reconocidas como tales, se cree en ellas, y hay acuerdo humano de asignar ese status a determinados fenómenos; esa asignación se puede formular como una regla constitutiva - pues crea todo tipo de prácticas y rituales que antes no existían- y genera poderes deónticos — por ejemplo, los poseídos te pueden arrastrar a la posesión o maldecirte, los exorcistas pueden liberarlos, etc.- De este modo, y en el contexto adecuado, «Fulano está poseído por el demonio» pasa a constituir una proposición de hecho exactamente igual de verdadera que «tengo un billete de 100 euros en el bolsillo» o "estoy casado con Zutana». Si a Searle esta conclusión le molesta, deberemos plantear entonces la siguiente pregunta: ¿hay alguna diferencia entre ambos tipos de hechos, las "posesiones demoníacas" y el dinero o el matrimonio? Responder a esto nos llevará a cuestiones que trataremos en las próximas secciones, pero parece claro que algo tiene que ver esta - a mi entender indeseable - consecuencia con el mentalismo de nuestro autor a la hora de establecer en qué consiste la realidad social e institucional.

Hasta aquí he intentado mostrar que la aportación de Searle no nos aleja mucho del "construccionismo social», y he sugerido que eso puede tener consecuencias idealistas no muy deseables. Para acabar esta sección, quisiera decir que, aunque lo anterior sea cierto, el mérito de Searle todavía sería notable: habría sido el primero en haber explicado y fundamentado el "construccionismo" con suficiente rigor lógico y formal. Como muestra Hacking (1999), al 
hacer tal cosa los «dientes» del «construccionismo» parecen mucho menos afi$\operatorname{lados}^{11}$.

\section{3. ¿ES POSIBLE SUPERAR EL MENTALISMO?: HACIA UNA ONTOLOGÍA SOCIAL MATERIALISTA}

Como afirma Domènech en el prólogo al libro de Searle, habría dos maneras de intentar discutirle a éste su división del mundo en "hechos brutos» y «hechos mentales-sociales-institucionales». La primera es la «construccionista universal», que ya hemos descartado, consistente en afirmar que todos los hechos son institucionales o sociales. La segunda, por el contrario, sería la de negar que haya hechos institucionales, es decir, la de mostrar, mediante algún tipo de reduccionismo, que todos los hechos institucionales pueden ser adecuadamente descritos y explicados en términos de otros hechos brutos (por ejemplo, biológicos, como pretenden la sociobiología o algunas ramas de la biología evolucionaria, o computacionales, como quieren algunos teóricos de la información). Creo que Searle argumenta convincentemente - más en otros libros que en éste- contra esas variantes de reduccionismo radical. Lo que propongo en las páginas que siguen es adoptar una estrategia alternativa de discusión, consistente en aceptar la distinción de Searle, pero negando su exhaustividad a la hora de explicar la realidad social e institucional, y hacerlo en la dirección de una ontología social no reductiva pero tampoco mentalista, sino materialista y práctica ${ }^{12}$.

El desafío de Searle es potente, y bien pudiera acabar, a la postre, obligándonos a abandonar o replantear alguno de los dogmas más queridos de la venerable tradición sociológica clásica. Para criticarlo de forma relevante, es preciso demostrar que en la constitución de los hechos sociales e institucionales intervienen hechos que no son ni "brutos" $n i$ "mentales", esto es, que hay una tercera categoría de hechos además de las que él propone, que son irreductibles a lo puramente «mental», sin ser, no obstante, hechos independientes de la existencia de seres humanos que tienen estados mentales. Antes de adentrarnos por esta vía hagamos, sin embargo, dos precisiones importantes: 1) Podría objetarse que lo

${ }^{11}$ Frazer (1997) ha observado que una de las confusiones más frecuentes tanto entre algunos "construccionistas» como entre algunos de sus críticos es la de pensar que porque algo sea «socialmente construido» tiene que ser «frágil» o «ilusorio». El problema es que, muchas veces, "construido socialmente» sólo quiere decir «social», "histórico", o "producto de la acción humana»; y parece que para este viaje no hacían falta alforjas, pues ya desde Vico sabemos que la sociedad no es producto de los dioses. Éste es el sentido trivial del "construccionismo" que Hacking llama «histórico» en su tipología (1999: 46).

${ }_{12}$ Evidentemente, este intento tiene mucho que ver con el de Marx, y con el de algunos marxistas o post-marxistas que, como Lukács (1978), Markus (1982) o Castoriadis (1975), han intentado desarrollar una ontología social de esas características. Mi intuición es que sería posible recuperar y reformular la idea ontológica general de esta tradición con las armas de la filosofía y la teoría social analíticas. 
que Searle hace en realidad es llamar «hecho mental» a todo aquel que depende de la existencia de la mente para existir; pero no puede ser así, dado que en ese caso el antirreduccionismo de Searle resultaría inconsistente o totalmente vacío: con el mismo argumento podríamos llamar a todos los hechos mentales "hechos biológicos», o incluso "hechos físicos», ya que su existencia depende de la existencia previa de vida o de materia física. Incluso aunque supusiéramos que todos los hechos sociales e institucionales son causados por estados mentales, eso no implicaría necesariamente que todos los hechos sociales e institucionales son estados mentales. 2) Por otro lado, el propio Searle afirma que su tipología es sólo de "ciertos tipos de hechos» y no pretende ser exhaustiva (p. 133); pero el ejemplo que nos da de esos "otros tipos» consiste en los "hechos matemáticos», lo cual sugiere que no está pensando en lo mismo que nosotros; confirma esa impresión el que Searle nunca se refiera a otros tipos de hechos que no sean mentales o brutos en la constitución de las instituciones.

\section{LA «ACEPTACIÓN» DE LOS HECHOS INSTITUCIONALES}

Como se ha sugerido, en el planteamiento de Searle hay varias cosas que pueden resultar intuitivamente indigestas a muchos sociólogos. Empecemos por una de las más evidentes: decir que las instituciones requieren para existir el «acuerdo» o la «aceptación» de los seres humanos, esto es, "que los individuos directamente implicados y un número suficiente de miembros de la comunidad relevante, deben seguir reconociendo y aceptando la existencia de esos hechos» (Searle, 1995: 128); decir, aún más, que esos hechos consisten en ese acuerdo o reconocimiento (que el acuerdo es constitutivo de la institución), parece traer a nuestra mente fantasmas consensualistas y funcionalistas con implicaciones claramente conservadoras. Parece dejar fuera el poder, la costumbre o la tradición como explicaciones del mantenimiento de muchas instituciones sociales. Pero, si hemos de ser justos, estos fantasmas no afectan realmente a Searle. En primer lugar, él nunca deja de hablar del poder: lo que hacen las funciones de asignación de status es precisamente crear poder (o poderes deónticos, en su terminología; ibid.: 106 ss.); es más, el poder institucional, como algo distinto de la mera fuerza física bruta, consiste precisamente en una función de status; con lo que, para Searle, toda la vida institucional consiste en creación y destrucción de poder (ibid.: 122).

En segundo lugar, nunca dice Searle que ese "acuerdo» o "reconocimiento» deba ser libre, ni siquiera consciente: cuando habla de "acuerdo", "aceptación», o «reconocimiento", se refiere a poco más que a una aceptación pasiva o implícita de «las-cosas-como-son» (que nada tiene que envidiar al conocimiento "dado por supuesto" del que hablaban Schütz o Berger y Luckmann), cosas que no nos vamos a tomar la molestia de cambiar, ni de plantearnos siquiera si queremos cambiar. Los agentes, además, no tienen que estar pensando constantemente que "X cuenta como $\mathrm{Y}$ en el contexto $\mathrm{C}$ » para aplicar o hacer eficaz 
esa regla, ni explícita ni inconscientemente, sino que simplemente han de ser capaces de distinguir aquellas entidades a las que se asignan funciones de status de aquellas a las que no (Searle, 2001b).

En suma, Searle está lo suficientemente lejos del consensualismo parsoniano como para saber que en toda sociedad hay conflictos y desigualdades de poder, pero lo que dice es que esos conflictos consisten muchas veces en conflictos por la asignación de funciones de status, o se pueden formular en tales términos (y es difícil discutirle en este punto). También está lo suficientemente lejos del contractualismo liberal clásico (y de algunos más modernos): sabe perfectamente que las instituciones no se forjan porque de repente nos reunamos y decidamos hacerlas, sino que la mayoría acontecen por «evolución espontánea» y no intencionada ${ }^{13}$. Pero dilucidar esos procesos es tarea para la historia o la sociología empírica, no para una ontología social: lo importante es que esos hechos responden a la estructura lógica que Searle analiza.

Hay, sin embargo, un problema con su concepto de poder; o, más que un problema, una carencia (y carencia importante si, como manifiesta a veces, le interesa también elaborar una filosofía política en un futuro no muy lejano): no hay distinción clara entre dos casos de creación de hechos institucionales que a todas luces hay que diferenciar, pues tienen implicaciones normativas y explicativas muy diferentes. Veamos: por un lado, las instituciones pueden ir apareciendo y consolidándose por «evolución», como es el caso claro del dinero; pero, por otro lado, pueden darse casos en que realmente haya un cierto contractualismo real, en que "nos pongamos de acuerdo" todos los afectados en crear una nueva institución, o en llevar a cabo una asignación de función de status nueva ${ }^{14}$. Dicho de otro modo, cabría diferenciar entre «aceptación» como «acuerdo libre y consciente» o "no coaccionado», y "aceptación» como simple «no oposición activa» a unas determinadas instituciones. Searle (1997b: 453), en respuesta a una crítica de Tuomela (1997), dice que la aceptación no implica para él aprobación: pero entonces "aceptar» sólo significa en el fondo "no oponer resistencia física», y su significado cotidiano queda totalmente desvirtuado (siendo así que Searle no ha estipulado un significado teórico explícito para el término): ¿cómo podríamos entonces «no aceptar» una institución cuando se

${ }_{13}$ Aunque a veces roza la teleología conservadora en el peor estilo de Arnold Gehlen, como cuando dice que instituciones como el matrimonio o la propiedad existen porque «es mejor que haya un sistema de derechos, responsabilidades, deberes, obligaciones y poderes colectivamente reconocidos» (ibid.: 94), que constituyan un entramado estable de expectativas que no dependa de la pura fuerza bruta. Probablemente podemos estar de acuerdo en esto último, lo cual no necesariamente quiere decir que el matrimonio y la propiedad sean «mejores» que otras alternativas institucionales que puedan garantizar tal cosa (cosa que hasta un autor funcionalista como Merton sabía). Hay aquí una clara salida de tono ideológica (y conservadora) en un libro por lo demás bien sobrio y controlado en ese aspecto.

${ }_{14}$ Aquí entraría lo que Habermas (1992) llamaría poder comunicativo, lo que Arendt (1973) analizaba en algunos momentos revolucionarios, lo que Castoriadis (1975) estudiaba como creación de instituciones, es decir, todo tipo de procesos político-sociales democráticos, participativos, creadores de nuevas instituciones, etc. 
nos impone por la fuerza o por la coerción? Bien, parece claro que las implicaciones de la «aceptación» en ambos sentidos (la aceptación=pasividad y la aceptación=acuerdo libre y consciente) son totalmente distintas, y no sólo a nivel normativo (pues parece que la segunda responde más que la primera a criterios de justicia política), sino también a nivel explicativo, pues los mecanismos causales en juego son muy diferentes, dado que en el segundo caso intervienen con eficacia causal propia la racionalidad y la conciencia de los individuos implicados, cosa que no necesariamente ocurre en el primero, o al menos no al mismo nivel. Pero Searle, aunque advierte que ambos casos son posibles, no le da más importancia al asunto y pasa rápidamente a otra cosa. Sin embargo, para una teoría con alguna intención práctica (y Searle suele insistir, cuando fustiga a relativistas y antirrealistas, en que la filosofía debe responder de sus consecuencias prácticas para la vida), estudiar qué condiciones permiten una clase de «aceptación» más que la otra resulta de capital importancia.

Hay un segundo problema, relacionado con el "cuántos son suficiente» para que su "aceptación» constituya a un hecho como institucional. Searle dice que la aceptación o el reconocimiento de la función de status debe darse en un número suficiente de personas de la comunidad relevante. Sin embargo, ese número puede variar enormemente dependiendo de la institución, y no por casualidad: hay situaciones e instituciones que sólo requieren de un pequeño número de personas para ser objetivas y eficaces; el Derecho es una de ellas: la famosa máxima jurídica de que "la ignorancia de la ley no exime de su cumplimiento" no hace más que enunciar esto, dado que la mayoría de los ciudadanos ignora lo que dice el $95 \%$ del ordenamiento jurídico vigente. Esto implica que hay unas prácticas de poder previas al hecho institucional mismo. Ahora bien, Searle podría responder: esos poderes previos son poderes deónticos que, a su vez, dependen de una asignación de función de status: aunque no sepamos que "X cuenta como ilegal en C», sí sabemos que «Fulano cuenta como sabedor de lo que es ilegal o no en C», o «Fulano tiene poder deóntico para imponer el cumplimiento de la ley, sea ésta cual sea». Una vez más, para Searle, no tiene mucha importancia aquí el tema de "la gallina o el huevo» (qué fue primero, la asignación de poder a Fulano, o el establecimiento de la ley que Fulano hace cumplir), sino el hecho de que la estructura lógica «X cuenta como $\mathrm{Y}$ en C» describe adecuadamente las instituciones de este tipo. Pero, aun así, deberá admitir que tampoco carece de interés el que algunas instituciones (como las costumbres o hábitos sociales de saludo, vestido, trato social, gestos, etc.) requieran de una "aceptación» mucho menos contrafáctica que otras (como el Derecho), y supongan «sanciones» mucho más «simbólicas» y menos físicas para los ignorantes y/o incumplidores. Searle no nos da ninguna indicación de por qué se da esta diferencia, ni tampoco - y es a esto a lo que apuntamos_ - de en virtud de qué puede darse.

El problema del Derecho resulta interesante a este respecto, pues parece, en nuestra sociedad, la principal instancia capaz de asignar con eficacia funciones de status a los fenómenos (no por casualidad, la inmensa mayoría, con 
pocas excepciones, de los hechos que Searle nombra como institucionales son hechos jurídicos o juridificados; si se me permite añadir otro título más a la lista de sugerencias, a veces parece que su libro se podría llamar «La construcción de la realidad legal»). La pregunta es: ¿por qué el Derecho tiene una mayor eficacia que otros mecanismos a la hora de asignar funciones de status?, ¿no será quizá porque viene respaldado por la coerción y la violencia en última instancia?, ¿no vieron esto Hobbes, Marx o Weber con mucha mayor claridad que Searle?

Esto último nos lleva sin remisión al problema que deseábamos evitar, a saber, el de la "gallina y el huevo"; o, mejor dicho, nos lleva a plantear ese problema no sólo como histórico y sociológico, sino también como ontológico (que es lo que Searle se niega a hacer). Por ejemplo: en El Capital, Marx criticó la concepción del origen de la propiedad privada capitalista de la tierra como un proceso de «acumulación originaria» (1872: 891ss.); la realidad fue más bien que cuando todavía no existía esa propiedad como institución, ni las demás instituciones que la envuelven, algunos individuos se apropiaron por la fuerza de las tierras comunales, y fue entonces cuando apareció la función de status «X cuenta como propiedad de Fulano en el contexto C», así como «la propiedad de X da a Fulano tal y tal poder deóntico de disponer sobre X», etc. Bien, parece que esto no plantea problemas a Searle: en la medida en que hubo intencionalidad colectiva en esa apropiación, hubo un hecho social (aún no institucional) de acumulación originaria, que luego se convirtió en un hecho institucional mediante una asignación de función de status. Ahora bien, la pregunta que cabe plantear es la siguiente: ¿existiría —o podría seguir existiendo- ese hecho institucional de no existir una serie de prácticas de coerción material que le dan soporte? Dejemos aquí ahora esta pregunta, que retomaremos más abajo (en la sección 7), para intentar formular de manera más general todo lo que hemos sugerido hasta ahora.

\section{CREENCIAS VERSUS PRÁCTICAS}

La tesis a la que intento apuntar es la siguiente: una cosa es decir que los hechos institucionales requieren de la existencia de alguna creencia humana para existir, y otra muy distinta decir que existen sólo porque creemos que existen. Si al menos algunos individuos no fueran conscientes de la existencia de instituciones, no existiría la sociedad; pero no es esa conciencia lo que constituye el fundamento y el criterio para determinar su existencia, sino la acción, la actividad práctica, pues de lo contrario, ¿cómo podría existir la sociedad para quienes, hipotéticamente, no tuvieran conciencia de su existencia? Si existe también para ellos, es sólo porque la acción —no las creencias- de quienes sí tienen esa conciencia les envuelve, quieran o no, en relaciones y prácticas objetivas, o les influye materialmente. La conciencia de las instituciones, o la existencia de determinadas creencias sobre las mismas, es una precondición, pero 
no el único fundamento de la existencia de la sociedad y la realidad institucional. Dicho brevemente, las creencias o estados mentales constituyen una condición necesaria para esa existencia, pero no suficiente en muchos casos.

Sin embargo, Searle salta con facilidad de una cosa a la otra, y las implicaciones de este salto son claramente idealistas. Tomemos la afirmación de que los hechos institucionales existen sólo porque creemos que existen; el sentido que se le dé a este "porque» resulta clave: ¿en qué sentido son las creencias «causas» de las instituciones? Si echamos mano de la distinción aristotélica entre los cuatro tipos de causas, y dado que la intención de Searle es ontológica y no empírica, podemos suponer que se refiere más a las creencias como "causa formal» y "causa material» de las instituciones que como su «causa eficiente» o «final» (procesos que serían determinables sólo empíricamente en cada caso). Mi problema es que si las creencias pueden ser evidentemente "causa formal» de las instituciones ( $y$, por supuesto, "eficiente» $y$ «final»), sin embargo, no creo que puedan ser su "causa material», o no la única, o no siempre. En la medida en que Searle implique esto, su planteamiento es idealista e inadecuado.

Me interesa que quede claro cuál es el salto ilegítimo que da Searle: consiste en pasar sin más de decir que «el hecho institucional en cuestión sólo puede existir si es representado como existente» (1995: 78) a decir que «el acuerdo o la aceptación humana (...) resultan condiciones necesarias suficientes» para la existencia de instituciones (ibid.: 68); esta última tesis, o bien es trivialmente verdadera por definición estipulativa previa (que establezca la existencia de un acuerdo como condición lógica necesaria y suficiente de aplicación del nombre "hecho institucional»), o bien es falsa; $y$, en todo caso, derivarla de la primera es un clarísimo non sequitur: el que se necesiten representaciones para que haya hechos institucionales no implica deductivamente que estos hechos existan sólo en virtud de esas representaciones.

Searle afirma que «en el momento en que (...) todos o casi todos los miembros de una sociedad rechazan el reconocimiento de los derechos de propiedad, como en una revolución u otro tipo de revuelta, los derechos de propiedad dejan de existir en esa sociedad». Pero hay un matiz importante que no menciona: los derechos de propiedad no desaparecen sólo porque dejen de reconocerse subjetivamente, sino porque se actúa —objetivamente- para erradicarlos; no es un estado mental lo que los erradica, sino una acción práctica (y si esto suena al Marx de las Tesis sobre Feuerbach y La ideología alemana, la asociación es totalmente deliberada). Generalizando, las instituciones no existen sólo en la medida en que se crea que existen: una creencia por sí sola, directamente, no constituye un hecho institucional (ni siquiera sumada a un hecho físico bruto). El propio Searle observa que aunque yo no crea en las instituciones, no dejan de imponérseme: pero esto debería darle qué pensar sobre qué hay de constitutivo en un hecho institucional (o al menos en muchos de ellos) que no es, sin embargo, reductible a un hecho mental ni a un hecho físico bruto.

Bien, ¿qué es lo que hay? ¿Qué es «lo otro» que falta para constituir algo como hecho institucional, y que no son ni estados mentales ni hechos físicos 
brutos? ¿Qué es lo que funciona como "causa material» de las instituciones? Mi tesis, ya lo he sugerido, es que se trata ni más ni menos que del viejo concepto marxiano de praxis, de actividad práctica sensible. Es la praxis, la acción práctica, no la creencia como tal, la que completa la objetividad de los hechos sociales e institucionales. Son las prácticas humanas las que no se dejan reducir ni a hechos brutos ni a hechos puramente mentales ${ }^{15}$. Pongamos un ejemplo de los que le gustan a Searle: Aznar es presidente del gobierno, pero no lo es sólo porque (ni en la medida en que) le creamos presidente del gobierno, sino porque le votaron para serlo. Y aquí hay dos cosas: como dice Searle, hay una asignación de función de status («obtener más votos de los diputados cuenta como conseguir la presidencia») que es iterativa sobre otras («un papel X con el nombre de Aznar —o apretar un botón en el escaño- cuenta como un voto para Aznar», «un número $\mathrm{X}$ de votos ciudadanos para tal partido en tal circunscripción cuenta como un escaño de diputado", etc., etc.); pero hay también una práctica sensible de votar, una acción que no queda descrita ni recogida en esas proposiciones, y que es ontológicamente irreductible a la regla constitutiva «ir al colegio electoral y meter una papeleta en la urna cuenta como votar».

Recapitulemos; todo lo anterior nos lleva a un esquema ontológico de tres tipos de hechos, no dualista, como el de Searle:

1) Hechos brutos: independientes de la existencia de los seres humanos y de las instituciones (en el caso del dinero, las propiedades físicoquímicas de la celulosa u otros materiales).

2) Hechos mentales: la creencia, conciencia, o aceptación pasiva de que «el papel X cuenta como dinero (Y) en el contexto C».

3) Prácticas sensibles: las acciones o actividades prácticas de producción del papel o las monedas que cuentan como dinero, de circulación y utilización del mismo para diversas finalidades y en distintos contextos prácticos, etc.

Lo que he intentado argumentar es que todas ellas son condiciones necesarias, aunque ninguna es suficiente por sí sola para que exista el hecho institucional "dinero», y, en la mayoría de los hechos institucionales, son necesarias las tres.

15 En realidad, hay muchos hechos que resulta difícil encajar en esa dicotomía: las regularidades científico-sociales, o los "mecanismos» causales que estudian autores como Elster, o los dilemas y situaciones de interacción que analiza la teoría de juegos, o la desigualdad social y económica, ni son hechos brutos, pues requieren de instituciones para existir, ni son hechos puramente mentales. Sin duda, sería injusto decir que Searle ignora la práctica o la actividad humana (vid. 1995: 68-69 y 73), pero la trata secundariamente, sin explicitar cuál es su papel ontológico, y con la única intención de escapar al problema de la autorreferencialidad de las reglas constitutivas. 


\section{POR QUÉ LAS PRÁCTICAS SON CONSTITUTIVAS DE LAS INSTITUCIONES}

He defendido en la sección anterior la tesis de que las prácticas son también constitutivas de los hechos institucionales, pero aún de forma bastante intuitiva. ¿Qué quiere decir exactamente esa afirmación?, ¿en qué consiste el carácter constitutivo de las prácticas en los hechos institucionales? Mi respuesta, que intentaré argumentar en este epígrafe, es la siguiente: las prácticas son constitutivas de (muchas de) las instituciones porque deben ser efectivamente causadas por la asignación de función de status para que haya institución.

En cierto sentido, es sorprendente que Searle no llegue a esta conclusión, puesto que dispone de todas las herramientas conceptuales necesarias para ello. Su análisis del fenómeno de la «brecha» (gap) entre los estados mentales y la acción apunta precisamente en esta dirección:

«La brecha es aquel rasgo de la intencionalidad consciente por el que los contenidos intencionales de los estados mentales no se experimentan por el agente como algo que establece condiciones causalmente suficientes para decisiones y acciones, incluso en los casos en los que la acción es parte de las condiciones de satisfacción del estado intencional» (Searle, 2000a: 84).

Pues bien, éste es claramente el caso de la mayoría de los hechos institucionales: las condiciones de satisfacción de los estados intencionales que los constituyen requieren de actividades prácticas que no son automática o mecánicamente causadas por aquellos estados intencionales (esto es, por la creenciaaceptación de la regla constitutiva "X cuenta como Y en el contexto C»). Como se deriva de algunas aportaciones de Davidson (1980), Elster (1983) o Boudon (vid. Lizón, 2000), las creencias o, más en general, los estados mentales pueden ser considerados como causas de la acción, pero no son la acción: la relación entre creencia y acción no es tan mecánica ni tan automática como para que podamos prescindir de la distinción, pues se trata de dos momentos irreductibles, con implicaciones ontológicas bien diferentes, y ninguno de los cuales puede reducirse a "hechos brutos» en el sentido de Searle. Ahora bien, si algunas acciones o prácticas han de ser causadas para que la regla constitutiva se vuelva objetivamente eficaz, y si esas acciones son irreductibles a la regla misma, entonces esas acciones son también por sí mismas constitutivas del hecho institucional ${ }^{16}$.

¿Por qué no extrae Searle esta conclusión? Una vez más, parece que el mentalismo le juega una mala pasada a nuestro autor. En un indudable logro de

${ }^{16}$ De hecho, el propio Searle considera esas prácticas como necesarias para definir «Y» en la regla constitutiva, pero no da, sin embargo, el paso consiguiente: que entonces esas prácticas son también constitutivas del hecho; son, en términos aristotélicos, su "causa material». 
generalización, Searle (1995: 115 ss.) establece que lo que hace la asignación de función de status - y su aceptación - es capacitar o requerir de la gente determinadas formas de actividad práctica, esto es, crear poderes deónticos para actuar (o su reverso, limitaciones a la acción); pero esa actividad como tal no es considerada por Searle como constitutiva del hecho institucional, sino únicamente como una consecuencia fáctica contingente o un mero "síntoma» de la existencia de dicho hecho. Lo que dice, de forma un tanto ambigua, es que esa actividad es el contenido proposicional de la regla que se acepta, y que "para una amplia clase de casos el contenido tiene que ver con alguna modalidad de poder convencional en la que el sujeto se relaciona con algún tipo de acción o con algún curso de acciones» (ibid.: 115-116). Aquí las expresiones «tiene que ver» y "se relaciona con» merecerían una aclaración que no se encuentra en el libro. Tomemos el ejemplo del ticket de parking: aquí la creación de poder deóntico puede tener la forma «nosotros aceptamos que $S$, si no tiene ticket, paga una multa». La tesis de Searle parece ser que el hecho de pagar la multa si no se tiene el ticket es una mera consecuencia contingente de la regla constitutiva. Mi tesis, por el contrario, es que la realización efectiva de esas actividades, la ocurrencia de esas consecuencias, no es algo "posterior» - ni empírica ni lógicamente- al hecho institucional, sino que constituye el hecho en la misma medida en que lo hace la regla constitutiva y su aceptación. Dicho en términos menos formales: una regla que se "acepta" pero que no se cumple ni se hace cumplir no constituye institución alguna (y recuérdese el débil sentido que la palabra «aceptar» tiene aquí para Searle).

A la luz de lo anterior, cobra ahora su pleno sentido la afirmación de que la existencia de creencias (o de alguna creencia) puede ser una condición necesaria para la existencia de un hecho institucional, pero no suficiente en la mayoría de los casos si esas creencias no causan las prácticas correspondientes. No hay hechos sociales institucionales objetivos sin alguna conciencia humana de esos hechos o que tenga que ver con ellos, pero la pura conciencia de esos hechos no los constituye como tales hechos objetivos, sino que tiene que ser causa eficiente de prácticas que constituyan esos hechos.

Veamos algunos ejemplos. Imaginemos una prisión: es evidente que la mayoría de los participantes en esta institución (reclusos, vigilantes, gestores y cargos directivos, visitantes, proveedores, etc.) ha de creer que aquel edificio es una prisión para que efectivamente lo sea: la aceptación colectiva de la función de status «el edificio X cuenta como prisión en la ciudad C» es condición necesaria de existencia del hecho institucional. Pero eso no es suficiente: si todos simplemente creen que es una prisión, pero nadie actúa en consecuencia — vigila a los presos, los encarcela, les impide escapar, organiza las rutinas, impone castigos, etc., etc.—, aquel edificio no será de hecho una prisión ${ }^{17}$.

17 Y, a este respecto, los estudios de Foucault (1975), por muy discutible que pueda ser su arquitectura conceptual, muestran hasta qué punto si una cárcel es tal es más por una cuestión de prácticas que de creencias. 
Otro ejemplo puede ser el de una huelga: una huelga no es una huelga sólo porque se asigne al hecho de dejar de trabajar la función de status "huelga", sino porque se deja de trabajar materialmente, se reconozca o no como tal. Si los empresarios o los jueces no reconocen la huelga, la situación objetiva es la misma. Si los sindicatos declaran una huelga, pero los trabajadores acuden a su puesto, no hay huelga, pero no porque no la reconozcan, sino porque el hecho de no reconocerla causa una conducta material concomitante.

Así, las creencias han de causar algo que no son creencias para poder ser constitutivas de un hecho institucional. Y ese algo más no es un hecho bruto según la definición de Searle. Pero, aunque lo fuese, no por ello se evitaría que la tesis de Searle de que las creencias constituyen por sí solas las instituciones quedase dañada, pues no estaríamos hablando aquí del hecho bruto "X" al que se añade una función de status, sino del (supuesto) hecho bruto que es causado por la aceptación colectiva de esa asignación de función de status. En cualquier caso, considerar tal hecho como «no social» o «no institucional» resultaría, cuando menos, muy curioso.

Dos precisiones son convenientes para cerrar esta sección. En primer lugar, contra la objeción recurrente de Searle de que su planteamiento es ontológico y no causal o histórico, cabe aducir que el argumento que se ha expuesto no es empírico o causal, sino también lógico o conceptual. En el fondo, podríamos decir que el reconocimiento no es reconocimiento de una regla constitutiva, sino de una serie de prácticas materiales que hacen que la regla funcione: sin esas prácticas, no hay «regla constitutiva» que valga; luego estaríamos incluso tentados de pensar que no es la regla lo constitutivo, sino las prácticas, o, quizá mejor, que la regla no es más que las prácticas, lo que nos acercaría al Wittgenstein de las Investigaciones filosóficas (1953), y nos podría llevar, en el límite, a suprimir el concepto de asignación de función de status por «mutiplicar los entes sin necesidad». Dejemos simplemente esta sugerencia encima de la mesa, pues discutirla nos llevaría mucho más lejos de lo que ya hemos ido. Baste observar que una cosa es describir prácticas en forma de reglas lógicas, y otra distinta acabar diciendo que son las reglas lógicas y no las prácticas las que tienen una realidad ontológica (¿no planea por aquí el fantasma de Hegel?). En suma, a la - ciertamente correcta- "primacía lógica de los hechos brutos sobre los institucionales», que defiende Searle, ¿no habría que añadirle la «primacía lógica de la praxis sobre las creencias, el reconocimiento, y las funciones de status»?

La segunda precisión es la siguiente: se observará que hemos estado matizando que las prácticas son constitutivas de la mayoría o de muchos hechos institucionales. En efecto, en aquellos casos, analizados por Searle, de hechos institucionales "puramente honoríficos» en los que no existe creación de poder deóntico (como pueden ser las menciones o cargos honoríficos, o, a la inversa, las reprobaciones o pérdidas de honor), tampoco existirían en principio prácticas que fueran constitutivas del hecho como tal, y bastarían la «aceptación» o las creencias para su existencia. Esto no debe extrañarnos, pues, como se verá 
más en detalle en la sección 7, el que las prácticas sean constitutivas de las instituciones está estrechamente relacionado con la creación de poderes deónticos, de tal modo que, si éstos no existen, las prácticas dejan de ser centrales.

En resumen: exceptuando los hechos institucionales de tipo "honorífico", si la creencia de que "X cuenta como $\mathrm{Y}$ en el contexto C» no causase las prácticas pertinentes, no habría hecho institucional; pero si la creencia causa esas prácticas, entonces el hecho institucional es algo más que un hecho mental superpuesto (directamente o por iteración) a un hecho bruto.

\section{EL PROBLEMA DEL PODER}

En la sección 4, al hilo del concepto de «aceptación», ya abordamos de forma algo superficial algunos problemas que la teoría de Searle tiene por lo que hace a las relaciones de poder. Abundaremos ahora algo en esta cuestión, pues el modo que tiene Searle de entender el poder es, una vez más, típicamente idealista.

Hemos de distinguir dos tesis a este respecto en el libro de Searle: la primera es que del mismo modo que las instituciones sólo existen para él en la medida en que creamos que existen, así el poder institucional en general sólo existe en la medida en que sea reconocido como tal ${ }^{18}$. Searle distingue entre el poder físico bruto y el institucional, que también denomina convencional o deóntico; el poder deóntico es el que crean las reglas constitutivas que asignan funciones de status. Ya hemos criticado suficientemente esta tesis en su formulación más general, así que no insistiremos más: las prácticas por las que se ejerce ese poder deóntico son tan constitutivas de las instituciones como las citadas reglas.

La segunda tesis idealista de Searle sobre el poder es la que nos ocupará ahora. Tiene que ver con el famoso problema de "la gallina y el huevo», que dejamos pendiente en la sección 4. Searle afirma no sólo que el poder convencional consiste en reconocimiento, sino también que el poder bruto suele depender en última instancia del poder convencional, o, dicho en otros términos, que el «sistema de fuerza» depende normalmente del «sistema de aceptación», más que lo contrario (1995: 104 ss.). Según esto, un ejército no es aceptado porque disponga de armas, sino que dispone de armas y las puede usar porque es aceptado como ejército; y esto es así porque, en el fondo, el ejército o la policía no son más que sistemas de funciones de status.

Sin embargo, el ejemplo que pone Searle acaba por socavar su propia tesis: me refiero a la caída de los regímenes soviéticos de Europa del Este. Searle afir-

${ }^{18}$ En esto está cerca del concepto de poder de Arendt (1973) y, también, como advierte De Lara (1997), de la noción de Bourdieu (1994) de "violencia o dominación simbólica», que existe sólo en virtud del reconocimiento que obtiene el dominador por parte del dominado; podría decirse que, para Searle, todo poder institucional es poder simbólico en el sentido de Bourdieu, esto es, es generado por la creencia de que es un poder. 
ma que estos regímenes cayeron cuando su «sistema de funciones de status dejó de ser aceptado» (ibid.: 105). Pero, como él mismo admite más tarde, ese sistema dejó de ser aceptado de hecho mucho tiempo atrás, y fue mantenido por el miedo, el control, la coerción y, cuando fue necesario, la fuerza policial y militar. Dicho algo groseramente, de poco hubiera servido a la gente «dejar de aceptar» que "Fulano cuenta como policía en Polonia o en la RDA» si Fulano tiene un arma y está dispuesto a usarla contra quien cuestione esa función de status, independientemente del reconocimiento que pueda tener la misma. Y es que, cuando cayeron dichos regímenes, no fue porque la población simplemente "dejara de aceptarlos», sino porque actuaron en coherencia con esa falta de aceptación que ya existía hacía tiempo: saliendo a la calle, cruzando el muro, etc. Y eso ocurrió sólo cuando la amenaza del uso de la fuerza se tornó implausible (veinte años antes no hubiera sido así). De modo que el ejemplo acaba probando lo contrario de lo que pretende Searle: si fue posible mantener por la fuerza un régimen "no aceptado" durante cuarenta o setenta años, entonces es que hay situaciones empíricas en que el «sistema de aceptación» es impotente e irrelevante frente al "sistema de fuerza», hasta que éste se debilita, y entonces el primero se puede manifestar a través de las acciones prácticas correspondientes (a menos que Searle diga que el simple no derrumbamiento de un sistema equivale a su aceptación tácita, con lo que todo su argumento se convierte en tautológico). ¿Acaso no ha habido más poderes impuestos que aceptados en la historia de la humanidad? Como sabía Marx, «el poder del Estado no flota en el aire» (1852: 348).

Creo que estos problemas son debidos a que no es cierto que el ejército o la policía sean primordial o únicamente sistemas de funciones de status. Según la definición de Searle, una asignación de función de status es siempre necesaria cuando "X» no puede cumplir la función sólo en virtud de sus características físicas. Pero el ejército o la policía pueden perfectamente cumplir algunas de sus funciones en virtud de sus solas características físicas: las armas de que disponen son algo más que un «marcador» de status; su utilización se basa en funciones agentivas causales (como en el caso del destornillador o el automóvil), no de status. Lo que puede ser un hecho institucional es que el ejército sea reconocido oficialmente como el Ejército del Estado $\mathrm{X}$, con unos derechos $\mathrm{y}$ unas obligaciones; pero las prácticas violentas del ejército como tal no consisten en una función de status, sino en una función causal. Y pueden constituir, por tanto, un ejemplo de cómo el «sistema de aceptación» depende en muchas ocasiones del «sistema de fuerza».

Pero la violencia física bruta no es el único mecanismo posible de coerción. Si generalizamos, veremos que en las instituciones hay muchas instancias que se utilizan para ejercer coerción sobre los individuos: promoción, empleos, salarios, penas, sentencias, notas de curso, etc., y aunque muchas no son materiales, sino simbólicas o dependientes de aceptación, al final acaban siéndolo en el sentido de que aumentan o disminuyen el bienestar material de las personas (quienes además son plenamente conscientes de ello y suelen buscar maxi- 
mizar ese bienestar por varios medios): como dice Celano (1999), la mayoría de las instituciones dan poderes convencionales para, en última instancia, realizar actos no institucionales de apropiación o disfrute de bienes y servicios. El dinero es, una vez más, un ejemplo excelente: no únicamente nos da el poder deóntico de comprar, vender, invertir, etc., sino que da a quienes disponen de él en grandes cantidades otros poderes no institucionales, pues no hay ninguna regla constitutiva que diga que "tener grandes cantidades de dinero cuenta como tener poder o influencia política en X», o "cuenta como tener poder de chantaje económico sobre el gobierno», etc. Y, sin embargo, esos «otros poderes» parecen sumamente importantes a la hora de entender nuestra sociedad y nuestras instituciones.

Ahora podemos ver que las dos tesis de que hablábamos están relacionadas: si el poder institucional no depende sólo del reconocimiento, sino de prácticas, entonces es que hay poder físico dándole soporte "desde fuera» de las reglas constitutivas; pero entonces se sigue que el poder físico no puede depender casi siempre del institucional, sino que muchas veces ocurrirá lo contrario (y la medida en que ocurra lo uno o lo otro probablemente tendrá mucho que ver con la distinción que hicimos entre «aceptación como no-oposición o pasividad» y «aceptación como acuerdo libre y consciente»). La frontera entre los Estados Unidos y México (como en su día el muro de Berlín) no existe sólo por su "ser reconocida como frontera", sino por la coerción física, los controles materiales y las sanciones que la mantienen como tal. Si todo esto no existiera, ningún «reconocimiento colectivo» podría evitar que dejara de ser una frontera. Lo que sostiene el reconocimiento de que «X es la frontera entre USA y México" es algo más que el reconocimiento. $Y$ en este caso, como en el caso de la «acumulación originaria» que describía Marx, no es el «sistema de fuerza» lo que depende del «sistema de aceptación», sino exactamente al revés.

En definitiva, además de - e incluso previamente a- la asignación de funciones de status, debe haber, en última instancia, prácticas de individuos que pueden imponer coercitivamente esa asignación o bien sancionar su no-reconocimiento, y que pueden hacerlo por motivos físicos que tienen que ver con funciones causales, no de status. Esto es clave para desarrollar las buenas intuiciones de Searle en la dirección de una ontología social materialista, no mentalista.

\section{A MODO DE CONCLUSIÓN}

Podemos ahora cerrar el círculo retomando una cuestión que apareció en la sección 2. El añadir las prácticas a las creencias como constitutivas de la realidad social evita que las posesiones demoníacas sean tan reales como el dinero. Lo que es real es que hay gente que cree en posesiones demoníacas, y que lleva a cabo ciertas prácticas sobre la base de esa creencia, pero esas posesiones como tales no existen en virtud de que se crea en ellas; para que existieran como tales deberían existir las prácticas que constituyen la referencia explícita de esas 
creencias, a saber, los demonios que se introducen en nuestro cuerpo, etc. Y hasta el momento no hay noticia de que esas prácticas existan.

Si las creencias en las posesiones demoníacas no pueden forjar por sí solas la realidad de las mismas, tampoco pueden forjar sin más la realidad de la mayoría de los hechos institucionales, esto es, de la existencia de reglas del tipo "X cuenta como $\mathrm{Y}$ en el contexto $\mathrm{C}$ ». "Y» no puede existir sin toda una serie de prácticas y relaciones de poder, y aunque pueda causar la creación de nuevos poderes deónticos (como el del brujo o del exorcista), esos poderes sólo existen y se ejercen en la mayoría de los casos como actividades prácticas. Si esto es así, entonces las preocupaciones ontológicas de Searle están estrechamente imbricadas con cuestiones normativas (como la legitimidad de determinados poderes deónticos), y deberían ampliarse a éstas, con lo que nos introduciríamos ya en otras aguas muy distintas, aunque no menos agitadas. Por lo que hace a las anteriores líneas, me contentaría con haber argumentado de forma convincente que es posible desarrollar una ontología social materialista que pueda resolver algunas de las limitaciones del — por otra parte admirable_ intento de Searle.

\section{BIBLIOGRAFÍA CITADA}

AREndt, Hannah (1973): Crisis de la República, Madrid, Taurus.

BARnes, Barry (2001): "On The Construction of Social Reality", Revue Internationale de Philosophie, n.o 217 (junio).

Berger, Peter L., y LuCKMann, Thomas (1966): The Social Construction of Reality, London, Penguin, 1967.

Bourdieu, Pierre (1994): Razones prácticas. Sobre la teoría de la acción, Barcelona, Anagrama, 1997.

Castoriadis, Cornelius (1975): The Imaginary Institution of Society, Cambridge, Polity Press, 1987.

Celano, Bruno (1999): «Collective Intentionality, Self-referentiality, and False Beliefs: Some Issues Concerning Institutional Facts», Analyse \& Kritik, n. ${ }^{\circ} 21$.

Corsten, Michael (1998): «Between Constructivism and Realism: Searle's Theory of the Construction of Social Reality», Philosophy of the Social Sciences, vol. 28, n. 1 (marzo).

Davidson, Donald (1980): Essays on Actions and Events, Oxford, Clarendon Press.

DE LARA, Philippe (1997): "Un mirage sociologique. La "construction sociale de la réalité"», Le Débat, n. ${ }^{\circ} 97$ (noviembre-diciembre).

DREYFUS, Hubert L. (2001a): "Phenomenological Description versus Rational Reconstruction", Revue Internationale de Philosophie, n. 217 (junio).

- (2001b): «The Primacy of Phenomenology over Logical Analysis» (texto no publicado; disponible en http://ist-socrates. berkeley.edu/-hdreyfus).

DURKHEIM, Émile (1895): Las reglas del método sociológico, Barcelona, Orbis, 1985.

- (1898): «Representaciones individuales y representaciones colectivas», en Sociología y Filosofía, Madrid, Miño y Dávila, 2000.

ELSTER, Jon (1983): Uvas amargas. Sobre la subversión de la racionalidad, Barcelona, Península, 1988.

FouCaUlt, Michel (1975): Vigilar y castigar, Madrid, Siglo XXI, 1996.

Frazer, Elizabeth (1997): «Construction and Social Construction (review of John Searle's The Construction of Social Reality)", Imprints, vol. 1, n.o 3 (marzo).

Habermas, Jürgen (1992): Facticidad y validez, Madrid, Trotta, 1998. 
HackING, Ian (1997): «Searle, Reality and the Social», History of the Human Sciences, vol. 10, n. 4 (noviembre).

- (1999): ¿La construcción social de qué?, Barcelona, Paidós, 2001.

Heidemann, Carsten (1999): «On Some Difficulties Concerning John Searle’s Notion of an "Institutional Fact" ", Analyse \& Kritik, n. 21.

Hornsby, Jennifer (1997): «Collectives and Intentionality», Philosophy and Phenomenological Research, vol. LVII, n.o 2 (junio).

Hund, John (1998): "Searle's The Construction of Social Reality», Philosophy of the Social Sciences, vol. 28, n. ${ }^{\circ} 1$ (marzo).

LagersPetz, Eerik (1999): «John Searle’s Social Ontology», Analyse \& Kritik, n.o 21.

LIZÓN, Ángeles (2000): "Del "efecto Simmel” y la autopersuasión: la teoría cognitivista de las creencias de R. Boudon", Papers. Revista de Sociologia, n. 62.

LUKÁCS, Georg (1978): The Ontology of Social Being, London, Merlin Press, 1978-1980.

MARKUS, Gyorgy (1982): Language and Production. A Critique of the Paradigms, Dordrecht, D. Reidel Publishing Company, 1986.

MARX, Karl (1852): El dieciocho Brumario de Luis Bonaparte, Madrid, Espasa-Calpe, 1985.

- (1872): El Capital. Crítica de la economía politica. Libro I: El proceso de producción del capital (3 vols.), México, Siglo XXI, 1990 (vol. 1) y 1988 (vols. 2 y 3).

MejJers, Anthonie W. M. (2000): «Social Reality, Relations and Searle’s Ontological Individualism» (texto no publicado; disponible en http://wings.buffalo.edu/philosophy/Farber/meijers. html).

Noguera, José Antonio (1999): «El neo-idealismo sociológico: Para una crítica de La construcción social de la realidad, de Peter L. Berger y Thomas Luckmann», texto presentado en el III Congrès Català de Sociologia (Lérida, abril de 1999).

Osborne, Thomas (1997): "The Limits of Ontology», History of the Human Sciences, vol. 10, n. ${ }^{\circ} 4$ (noviembre).

Ruben, David-Hillel (1997): "John Searle's The Construction of Social Reality", Philosophy and Phenomenological Research, vol. LVII, n. ${ }^{\circ} 2$ (junio).

SEARLE, John R. (1995): La construcción de la realidad social, Barcelona, Paidós, 1997.

- (1997a): "Responses to Critics of The Construction of Social Reality", Philosophy and Phenomenological Research, vol. LVII, n. 2 (junio).

- (1997b): "Reply to critics of The Construction of Social Reality", History of the Human Sciences, vol. 10, n. ${ }^{\circ} 4$ (noviembre).

- (1998): «Social Ontology and the Philosophy of Society», Analyse \& Kritik, n. ${ }^{\circ} 20$.

- (2000a): Razones para actuar. Una teoría del libre albedrio, Oviedo, Ediciones Nobel.

- (2000b): "Langage, conscience, rationalité: une philosophie naturelle. Entretien avec John Searle», Le Débat, n. 109 (marzo-abril). Disponible en http://ist-socrates.berkeley.edu/-jsearle.

- (2001a): «Meaning, Mind \& Reality», Revue Internationale de Philosophie, n. 217 (junio).

- (2001b): «Neither Phenomenological Description Nor Rational Reconstruction: Reply to Dreyfus», Revue Internationale de Philosophie, n.o 217 (junio). Disponible en http://ist-socrates. berkeley.edu/-jsearle.

- (2001c): «Ontology and Social Constructs. Reply to Barnes», Revue Internationale de Philosophie, n. ${ }^{\circ} 217$ (junio).

- (2001d): «Reply to Barry Smith», American Journal of Economics \& Sociology (en prensa).

SMITH, Barry (2001): «The Ontology of Social Reality», American Journal of Economics \& Socio$\log$ (en prensa).

TuOmela, Raimo (1997): "Searle on Social Institutions», Philosophy and Phenomenological Research, vol. LVII, n.o 2 (junio).

Waldenfels, Bernhard (1998): "Comment on John Searle's The Construction of Social Reality", Analyse \& Kritik, n. ${ }^{\circ} 20$.

WeTtersten, John (1998): «The Analytical Study of Social Ontology: Breakthrough or Cul-deSac?», Philosophy of the Social Sciences, vol. 28, n. ${ }^{\circ} 1$ (marzo).

WiTTGENSTEIN, Ludwig (1953): Investigaciones filosóficas, Barcelona, UNAM-Crítica, 1988. 


\begin{abstract}
This article carries out a critical analysis of some aspects of John R. Searle's work The Construction of Social Reality (1995). Starling out from agreement with Searle on the need to abandon the so-called "social constructionism», an appraisal is made of the extent to which the author's argument is successful in this endeavour. In this regard, the following theses are defended: 1) Searle's social ontology is partially weighed down by inappropriate mentalism, in other words, by the reduction of all social facts to mental facts or representations superimposed on «rough" facts. 2) Searle's mentalism does not take him sufficiently far away from social constructionists, but in spite of himself his coherent development ends up having constructionist and idealistic consequences. 3) In order to overcome these limitations, it should be demonstrated that there are social facts that are not rough facts, or mental facts, or simple combinations of both; it shall be maintained that an analytically reconstructed concept of praxis can be a good point of departure for developing this strategy, which may be a step in the construction of a materialistic social ontology.
\end{abstract}

